\title{
Iconic Power: Materiality and Meaning in Social life
}

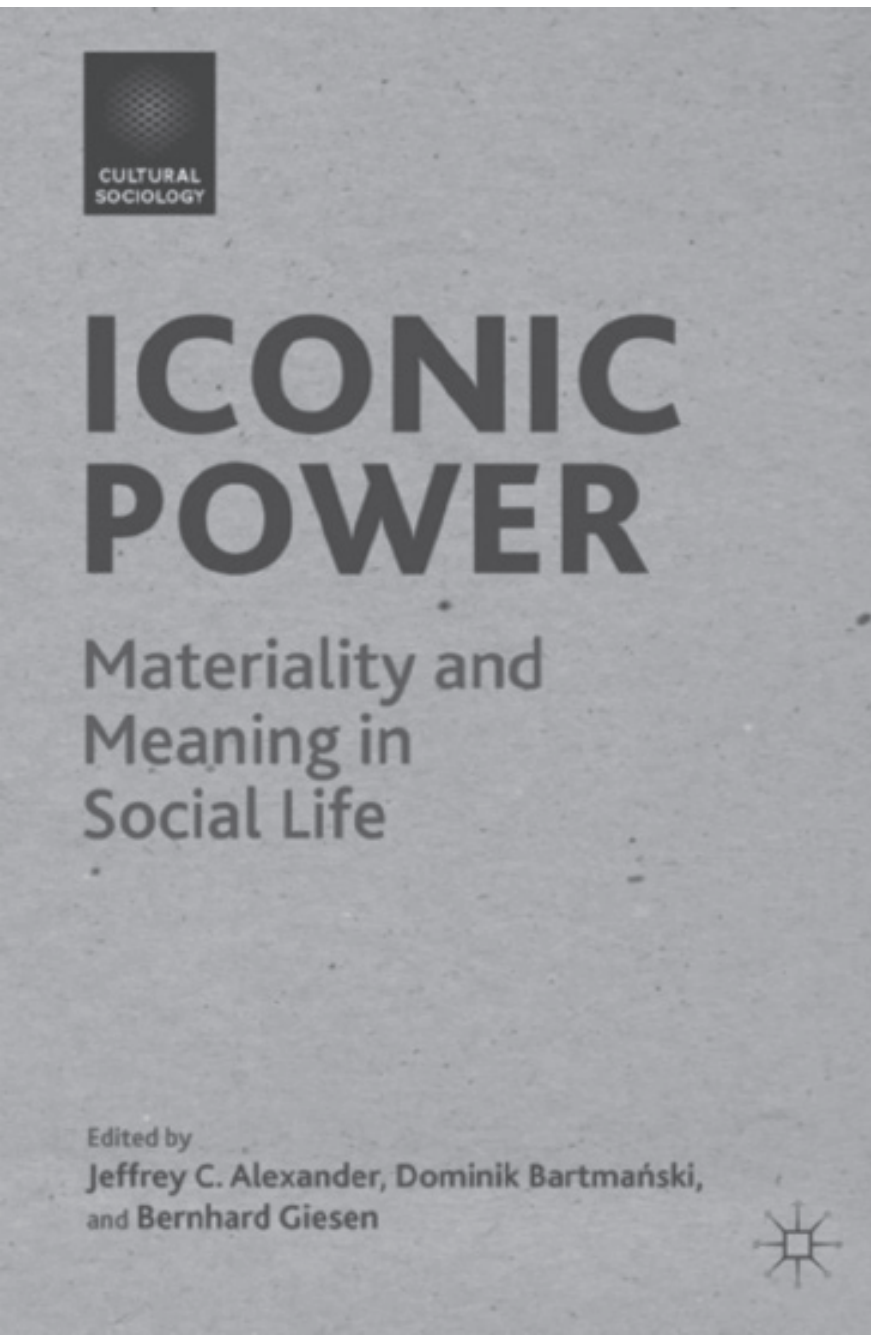

\section{Editores:}

Jeffrey C. Alexander; Dominik Bartmanski \& Bernhard Giesen

Año:

2012

\section{Editorial:}

Springer

Reseña elaborada por: Juan Carlos Patiño Prieto ${ }^{1}$

${ }^{1}$ Coordinador de Estudios y Gestión Cultural Virtual - Facultad de Estudios en Ambientes Virtuales de la Universidad EAN. 
L

a pervivencia histórica de los íconos se sustenta en su capacidad de sintetizar significados y sentidos necesarios para la interrelación humana $y$ en su utilidad como atajos cognitivos que funcionan como referentes temporales, culturales, históricos. De esta manera, el ícono se revela como una puerta de entrada a la información que ha sido codificada para generalizarla y hacerla convencional. Así, quienes reconocen el ícono pueden participar en la vida socio-cultural a través de los significados compartidos. El ícono como construcción cultural provee imágenes de fácil acceso para el espectador y posibilita desde este punto, la configuración de comunidades que se identifican alrededor de sus sentidos. Esta resiliencia y poder de lo icónico a través del tiempo, radica en la capacidad que tienen sus audiencias para transformarlos sin perder su esencia, en su capacidad de adecuar sus sentidos y significados a las circunstancias de cada momento (Alexander et al, 2012).

En relación con los trabajos de investigación recientes que están vinculados a la transformación de eventos históricos o artefactos culturales en íconos de referencia social, política, artística o todas a la vez, la principal compilación de ensayos la constituye el libro titulado Iconic Power: Materiality and Meaning in Social Life editado por Jeffrey Alexander, Dominik Barmanski y Bernhard Giesen. Este libro publicado en el año 2012 cuenta con cuatro capítulos que exponen catorce trabajos de investigación relacionados con la iconicidad por parte de diferentes autores. Los principales abordajes teóricos que reúne este libro podrían ubicarse en cuatro ejes: la materialidad generada en torno a acontecimientos históricos de gran recordación; las prácticas creadas por grupos en torno a objetos identitarios para un grupo social; las representaciones e imaginarios que se instauran a partir de las estrategias de comunicación social, periodística y publicitaria; y por último, el análisis hermenéutico de los íconos en cuanto al andamiaje conceptual que los soporta y las reflexiones que posibilitan en diversas disciplinas.

Iconic Power recoge disertaciones teóricas relacionadas con lo que Gottfried Boehm (2012) Ilama la 'diferencia icónica' a través de su investigación sobre la presencia material de las imágenes y lo que estas representan, con respecto a lo que está ausente en la representación y la realidad imaginada. Los ensayos del libro que se apoyan en este paradigma y continúan esta discusión son de Wender Binder, Bernhard Giesen, Valentin Rauer y Daniel Šuber, (Alexander et al., 2012, p. 248). Por otra parte, desde una posición que busca sintetizar el concepto de lo icónico y exponerlo en el centro de sus argumentos, están Jeffrey Alexander, Dominik Bartmanski y Fuyuki Kurasawa. De la misma manera, Iconic Power contiene diversas perspectivas de análisis e interpretación de lo icónico que juntan la iconografía y la iconología. Es decir, discursos en los que los objetos de estudio se analizan desde su importancia como referentes históricos ubicados espacialmente en un escenario particular, 
hasta su capacidad para generar múltiples emociones a diferentes tipos de públicos alrededor del mundo (Šuber y Karamanic, 2012). Además de los tópicos mencionados, los autores desarrollan otros, tales como la manera en que se buscó la solidaridad de occidente ante la hambruna rusa de 1921, las estadísticas del VIH en los medios de comunicación, la constitución de un bien icónico como los vinos de la granja Penfol en Australia o el recordado Festival de Woodstock en 1969.

Una rápida descripción de algunos de los ensayos publicados en Iconic power, materiality and meaning in social life nos permite reconocer cuáles han sido algunos de los más recientes trabajos que tienen como punto de referencia el andamiaje conceptual proporcionado por los estudiosos del giro icónico. En el caso de Fuyuki Kurasawa, en su texto The making of visual Icons: On the 1921-1923 Russian Famine as Foundational Event, su principal punto de análisis es la manera en que se establecieron las campañas contra la hambruna en Rusia. El análisis se detiene en la forma en que fueron empleados, tanto el lenguaje verbal y el pictórico por parte de la propaganda, para persuadir a los países de Occidente de ayudar a los niños que sufrieron durante este período. El autor analiza la manera en que se apeló a lo emocional, la culpa y a los demás valores sociales que trascendieran la caridad, a través de una economía visual icónica que logró establecer un movimiento humanitario. Una de las imágenes que considera tuvieron mayor resonancia en occidente fue la de una ilustración en la que aparece una familia hambrienta, acompañada de un encabezado como "La más terrible devastación que ha afligido al mundo por siglos [...] El desamparo que sufren reclama su consideración. Cada minuto es precioso, por eso, envíe todo lo que pueda ahora. Los niños agonizan mientras usted lee y titubea" (Kurasawa, 2012: 68). Las principales preguntas desarrolladas por estas reflexiones están basadas en el tipo de imágenes que adquirieron el estatus de icónicas al ser asociadas a la lucha contra la hambruna desde los diferentes sectores que buscaban establecer su discurso como el más trascendente frente a dicho flagelo. En este trabajo, Kurosawa resalta la manera en que:

El formalismo semiótico puede ayudar en la identificación de los regímenes simbólicos en la economía visual de la iconografía humanitaria; es decir, reconocer las convenciones iconográficas o regímenes de tipificaciones (repertorios representacionales compartidos y convenios regularizados de los signos) encontrados en imágenes de sufrimiento distante, creado o enmarcado por organizaciones humanitarias (Alexander et al., 2012, p. 70).

Esta configuración del lenguaje icónico dentro de la propaganda con el propósito definido de conmover a sus espectadores, busca establecer una gramática moral del humanitarismo, al reafirmar las prácticas de "lo bueno" y "lo correcto" cuando otras personas están sufriendo. Por supuesto, en 
estas representaciones también se hace un uso eficiente de las convenciones sociales tipificadas como las vinculadas con los valores cristianos y sentimientos colectivos, que permitieron llevar a grandes sectores sociales a volcarse a ayudar a quienes padecieron el problema de la hambruna, generando en ellos sentimientos como compasión, lástima, culpa, consternación e indignación.

Este análisis de las formas de mediación simbólica desde los mensajes publicitarios es similar al trabajo hecho por la socióloga Wendy Bowler (incluida en Iconic power). En su escrito Seeing Tragedy in the News Images of September 11, ella analiza la forma como los medios registraron la noticia del ataque del 11 de septiembre al World Trade Center en la ciudad de Nueva York y la manera en que es empleado el lenguaje para dar un sentido particular a la misma. Uno de los aspectos más importantes que destaca la autora es cómo las noticias relacionadas con el 9/11 mantienen una estructura narrativa que se corresponde con la fabulación trágica expuesta por Aristóteles². Así mismo, establece vínculos entre las imágenes que se hicieron icónicas al aparecer en los medios de manera continua y, por ende, el alcance de una amplia recordación del evento. De la misma manera, la permanencia de la noticia en los medios de comunicación por varias semanas constituyó un aspecto fundamental para la magnificación del evento como trágico y para que se fijara en el imaginario de los televidentes como punto coyuntural en la historia del país. Bajo esta mirada, Bowler se pregunta por cuáles son los hechos que tienen un cubrimiento noticioso, en cuáles de ellos se enfatiza, y a cuáles no se les da la misma relevancia por no considerárseles con la capacidad de conmocionar a los públicos.

De esta manera, lo que la socióloga denomina un "cubrimiento saturado" de los eventos traumáticos tanto por parte de las noticias como de las representaciones ficcionales, hace que el hecho prevalezca en el imaginario del público por ser funcional para agendas políticas con variados intereses (Leavy, 2007, p. 192). En esta medida, el camino que fija la iconicidad de los eventos traumáticos pasa, al mismo tiempo, por un proceso de apropiación, memoria y comercialización de sus narrativas. Así, el evento traumático termina siendo naturalizado a través de representaciones dirigidas a la cultura popular que pueden tener diversos efectos en la memoria colectiva. Por un lado, sirven para rastrear los cambios sociales que se han dado desde que el hecho real ocurrió y por otro, para subvertir las asunciones que se tenían del pasado, gracias a las fórmulas simplistas de enfatizar en los roles de bondad y maldad de protagonistas y antagonistas. 


\section{Otros estudios del ícono como construcción social de sentido}

Otro de los trabajos destacados acerca del ícono como construcción social de sentido, incluido en el libro Iconic power, es el de Werner Binder quien desarrolla un análisis comparativo a los íconos materializados en fotografías tanto de la Guerra de Vietnam (1955-1975) como del escándalo por la tortura de prisioneros en Abu Ghraib (2004). El autor propone que para el estudio de este tipo de íconos se deben tener en cuenta cuatro dimensiones: referencial, trascendental, sintagmática y abierta a paradigmas. Frente a las dos primeras, los íconos deben referirse a un hecho histórico fundamental en la memoria de todos y adquieren trascendencia en la medida que invita a sus espectadores a explorarla. Así mismo, el carácter sintagmático del ícono apela a la ruptura de la significación que ha creado en los espectadores, al punto de llevarlos a explorarlo, constituyéndolo así en un símbolo paradigmático del hecho al que se refiere. Estas características están entrelazadas entre la significación que ofrece el desplazarse continuamente entre su superficie como signo y la profundidad de sus sentidos.

Los planteamientos que refuerzan la caracterización de los íconos por parte de Binder están basados en el establecimiento de las relaciones entre la visualidad, las imágenes y los textos a partir de los aspectos que pueden encontrarse en los íconos seculares que han sido apropiados en la cultura popular. Para ello, asocia el significado de lo sagrado que prevalece en ellos y la manera en que estos se convierten en significativos en la vida social. Para Binder "Cada ícono cultural tiene su ritual o su comunidad de culto» (Alexander et al., 2012, p. 105) y para diferenciar el culto por el ícono secular de las expresiones de una comunidad de fanáticos, es necesario reconocer las emociones colectivas que prevalecen en el tiempo respecto al objeto de culto en contraposición a la efervescencia del objeto de fanatismo. En este sentido, las emociones colectivas tienen mucho más valor por su trascendencia en la memoria cultural y las prácticas que se llevan a cabo en torno al objeto de culto. De la misma manera, es en la esfera pública en donde se validan las significaciones de dichos objetos de culto, en la mayoría de casos, con la ayuda de los medios de comunicación (Alexander, 2012).

Por otra parte, uno de los aportes más significativos a la teoría del giro icónico lo realiza Dominik Bartmanski en su texto Iconospicuos Revolutions of 1989: Culture and Contingency in the Making of Political Icons incluido en Iconic Power (2015). En este trabajo, Bartmanski establece cinco características de la iconicidad para ser analizadas en un evento de gran recordación histórica como el de la caída del muro de Berlín. Las características que presenta como fundamentales para establecer las formas en que los eventos o los objetos se han hecho icónicos para una comunidad son su carácter aurático, totémico, arquetípico, citable y generador de audiencias. En este escrito, Bartmanski 
argumenta su proposición teórica basado en la interpretación de la cultura material que rodea la consagración de la caída del muro de Berlín en relación con la mediación simbólica y el performance social que se establecieron alrededor de esta. Uno de sus planteamientos que resume parte de sus proposiciones sobre la iconicidad es la necesidad de:

Conectar la cosa y su contexto en el nivel de experiencias incorporadas [...] poner las cosas en perspectiva histórica, trayéndolas en nuevas circunstancias y en los avances actuales es tan importante como reconocer las "raíces" y los avances del pasado. Y al hacer que ambos, el pasado y el presente vivan en nuestras palabras, tenemos que darnos cuenta lo que las cosas significaron en la práctica, cómo cambiaron la experiencia sensorial, qué hicieron posible estética y socialmente, por qué conmueven nuestros cuerpos y almas. Cuando los objetos culturales hacen esas cosas a través del tiempo, algunos de ellos cambian la historia (Bartmanski \& Woodward, 2015, p. 32).

En su texto Iconospicuos Revolutions of 1989: Culture and Contingency in the Making of Political Icons, Bartmanski analiza los diversos medios y las mediaciones que condujeron a hacer de la caída del muro de Berlín un evento icónico a nivel mundial. En primera instancia compara este acontecimiento con otros que ocurrieron en 1989 de gran importancia, pero que no alcanzaron el mismo reconocimiento. La caída del muro de Berlín termina por normalizar en el imaginario cotidiano de los diversos públicos al recordarse no solo como la reunificación política, económica y social de Alemania, sino como "el comienzo del fin del comunismo en Europa", como lo conmemoraría el diario (New York Times 09 de noviembre de 2009, citado por Bartmanski, 2012, p. 39). La construcción de este proceso de iconicidad está mediada por las cinco categorías analíticas mencionadas anteriormente y por la interpretación de aspectos como la resonancia cultural del ícono, su cubrimiento discursivo y pictórico, y las contingencias históricas en las que emergió y que promovieron su encumbramiento.

Uno más de los trabajos incluidos en Iconic Power es el titulado How to Make an Iconic Commodity: The Case of Penfolds' Grange Wine, realizado por lan Woodward y David Ellison. En su ensayo evidencian la forma en que la mediación de comunidades de interés como los coleccionistas y consumidores del vino Penfolds' Grange, han contribuido a través de sus prácticas, al engrandecimiento de esta marca como una de las más importantes en Australia. Para este propósito han empleado estrategias vinculadas con imaginarios colectivos que se relacionan con la idea de la vieja y la nueva nación, y la propia maduración del vino. A partir de este caso, Woodward y Ellison proponen que «además de ser una destilación concreta de valores colectivos, los íconos tienen un poder performativo especial: una capacidad de remover un tipo de inquietud, representando y recordando a las personas 
sus anhelos, ansiedades, tensiones y deseos inconscientes» (Alexander et al., 2012, p. 158). Woodward y Ellison definen la iconicidad como un estatus conferido por un proceso de construcción de consenso dentro de un campo cultural por varios actores interesados, quienes forman un sentido colectivo de su valor. Las denominadas cualidades icónicas de un objeto son el producto de procesos de construcción de sentido y significado por parte de un grupo cultural, el cual, a través de una serie de simples, aunque numerosos actos en conjunción con varios textos integrales y puestas en escena, elevan un objeto a expresión suprema de un tipo particular o una clase de objetos. Los autores aseguran que los íconos deben tener influencia exterior en su esfera cultural inmediata, es decir que un ícono debe ser apreciado por conocedores y legos de igual manera (Alexander et al., 2012, p. 158).

Para cerrar este corto análisis de algunos de los trabajos expuestos en Iconic Power, vale la pena señalar los escritos por Julia Sonnevend y Piotr Sztompka. La primera autora presenta una teoría sociológica basada en el encuentro del espectador con las imágenes y plantea un modelo teórico social de la percepción que va más allá del entendimiento tradicional de la superficie y proyección, identificando los sentimientos individuales que participan en el encuentro. Así mismo, explica las negociaciones de sentido que se llevan a cabo en la interacción con las imágenes y los rituales icónicos que se dan a partir de este. Sztompka, por su parte, expone la manera en que el uso de la imagen ha dividido a la sociedad en exhibicionistas y voyeristas. A partir de este postulado, establece cuatro formas en la que las dos partes se encuentran: la sociedad del espectáculo, la sociedad del destape, la sociedad del diseño y la sociedad de los íconos. El autor propone que estas nuevas tendencias implican nuevos retos para la sociología al exponer la necesidad de crear un nuevo subcampo que podría denominarse la 'sociología visual' que requeriría nuevos métodos de observación y la necesidad de fortalecer una competencia que denomina como 'imaginación visual'

Las traducciones hechas a los diferentes textos son propias del autor de la presente reseña.

Traducción propia: "semiotic formalism can assist in the identification of symbolic regimes in the visual economy of humanitarian iconography, that is to say, iconographic conventions or regimes of typifications (shared representational repertoires and regularized arrangements of signs) found in images of distant suffering created or framed by humanitarian organizations" (Alexander, Bartmanski, \& Giesen, 2012, p. 70)

"Every cultural icon has its ritual or cult community". (Alexander, Bartmanski, \& Giesen, 2012, p. 105)

We need to connect the thing and its context al the level of embodied experiences [...] we put things in historical perspective, bringing in new circumstances and current developments is as important as recognizing the 'roots' and past developments. And to make both the past and the present alive in our words, we have to account for what things meant in practice, how they changed sensual experience, what they made possible aesthetically and socially, why they move our bodies and souls. As cultural objects do these things over time, some of them change history (Bartmanski \& Woodward, 2015, p. 32)

Beyond being a concrete distillation of collective values, icons also have a special performative power: a capacity to stir up and cultivate a type of restlessness, representing and reminding people of desires, anxieties, tensions, and subconscious wishes (Alexander et al., 2012, p. 158) 